ridge in Harrison County have their centres filled with silicious pebbly conglomerate, two conditions of existence which no known condition of carbonate of iron in the form of clay iron-stone could possibly create, even should we admit the existence of a sufficient quantity of that ore to form the vast deposits of iron as we now find them. The existence of the enormous quantities of carbonate of iron or clay iron-stone. I am by no means inclined to admit. Whether the lignitic ever held such quantities I do not know, but certainly the beds as we now find them contain very little of this class of ore. The little they do contain is almost altogether a sulphide.

\section{SORGHUM SUGAR.}

BY T. BERRY SMITH, FAYETTE, MO.

Tr has been many years since the people in the central and northern parts of the United States began to cultivate sorghum for the purpose of obtaining molasses therefrom. The processes were such as could be employed by almost any farmer.

But it has been only a few years since experiments began for the purpose of extracting sugar from the sorghum cane.

The first appropriation made by Congress for large experiments in sorghum sugar making: was during the last days of the session of 1884 . Since that time, so far as we know, annual appropriations have been made and untiring efforts put forth to improve both the cane and the processes of sugar making; and the advances made in each line have been steady and encouraging.

It is our purpose to treat mainly of the applications of scientific principles, as made in the government experiments in Kansas and elsewhere.

Let us suppose the cane has been grown under the ordinary circumstances and is ready to be harvested. The usual course is then to strip and top the cane, cut it and haul it to the mill (who that has heard its creaking, can ever forget it ?), there crush it and collect the juice, and then evaporate it to molasses by boiling in open pans, certain simple processes being employed to clarify the syrup more or less.

By such methods are obtained the molasses which we have all eaten and of which we can not mistake the peculiar flavor.

A brief analysis of the subject will show us that the main steps are:

r. Separation of the juice from the cane.

2. Separation of the sweets from the juice.

If we would manufacture sugar there must be a third step, viz. :

3. Separation of sugar from the molasses.

Let us treat these separately:

I.-Extraction of Juice.

Old Method: Expressing it by passing the cane between rollers.

New Method: Extraction by soaking in heated water, the process being termed diffusion.

The topped cane is delivered to the factory by the farmer. There it is cut into short lengths by a cutting machine, after which a fan blows away the boots, blades and trash, and then the short pieces are delivered to a shredding machine, which tears the cane into as small bits as possible.

This pulp is delivered to the diffusion battery, which is arranged in various ways, but the principle of which may be stated thus:

If hot water be poured over one jar of pulp it will soaik out a certain amount of the sugar content. If this sweetened water be withdrawn and moured over a second jar of pulp, it will become still more sweet; and by passing it in like manner over a number of jars of pulp, it will finally become as rich in extracts as the original juice of the cane was, $i$. e., it may be called cane juice.

Now in order to extract all the sweets, the first jar of pulp must be subjected to portion after portion of hot water, until there will be left in the pulp very little besides woody fibre. And so with the second jar and so with all the jars of pulp.

One can readily see that the jars or cells could be so connected that the hot water entering at No. $I$ would be forced in succession through a sufficient number to attain the desired strength, and thus the process be rendered continuous. Such an arrangement is termed a diffusion battery.

If the subject has been made plain so far, we are now ready to take up the second great step.

II.-Extraction of Sweets.

Old Method: Simple evaporation in open kettles or pans, with constant skimming to remove the "scum" formed by heat.

New Method: (r) Neutralization of acids by lime; (2) Removal of surplus lime by carbonic acid gas (carbonatation); (3) Heating and skimming; (4) Settling; (5) Evaporation of clear juice under reduced pressure and temperature.

The diffusion juice is placed in large tanks and milk of lime added until an alkaline reaction is shown. The purpose of this is to counteract the effect of any acids that may be present. At this point in our paper it will be necessary to digress a little and introduce a small amount of chemistry.

There are in the vegetable world many products which are composed of charcoal and water, the only difference in chemical constitution being in the proportions of charcoal and water employed.

Let us look at the accompanying table:

Wood $=6$ parts carbon and 5 parts water $\left(\mathrm{C}_{6} \mathrm{H}_{\mathrm{xo}} \mathrm{O}_{5}\right)$ Starch $=6$ " " " " 5 " " 5 " $\left(\mathrm{C}_{6} \mathrm{H}_{\mathrm{xo}} \mathrm{O}_{5}\right)$


Cane Sugar = $\mathrm{I}_{2}$ " " " $" \mathrm{II}$ " " " $\left(\mathrm{C}_{\mathrm{x} 2} \mathrm{H}_{22} \mathrm{O}_{\mathrm{xx}}\right)$

Now if we take wood, starch or cane sugar and boil them in water with acids, they will be converted into grape sugar. It is in this way that tons and tons of starch are annually changed into syrup and sugar for household and other purposes. Almost all of the clear thick syrups used on our tables at the present day are glucose or "grape sugar syrups. Such syrup is inferior to cane sugar syrup in the matter of sweetness, three pounds of cane sugar being equal to five ponds of grape sugar in this respect. You can plainly see, then, that the effect of the acids present in the diffusion juice would be to diminish the sweetness of the syrup produced by simply evaporating without their removal. Their removal is rendered easy by the use of lime, which neutralizes them by uniting with them to form insoluble compounds which settle to the bottom. Now as lime will combine with sugar also to form sucrates, it is necessary to remove any surplus lime that may be present, and this is done by blowing through the juices a stream of carbonic acid gas, which may be inexpensively obtained from the smoke stacks of the furnaces. This part of the process is known as carbonatation.

After neutralization and carbonatation, the juice is raised to the boiling point, the scum formed by heat is removed in the usual way, and then the clarified liquid is left in large tanks to settle. From these it is drawn off and is ready for concentration by evaporation. This is not accomplished in open pans because in an 
open pan the pressure of the atmosphere amounts to about fifteen pounds per square inch, and in order to raise the liquid to the boiling point this pressure must be overcome. If this pressure can be overcome, or at least largely reduced, then the boiling point can be reached at much lower temperatures than $2 \mathrm{I}^{\circ} \mathrm{Fahr}$.

The pressure is diminished by the use of air tight pans and of air pumps. Let us suppose that coils of pipe, connected with the escape pipe of the engine, are laid in a large pan, a supply of clarified juice fills the pan, an air-tight cover is put on, and the contained air is partially exhausted by the air pump. The exhaust steam from the escape pipe of the engine is hot enough to cause the juice to boil. Now let us suppose that the steam from this pan be forced through coils of pipe laid in another air-tight pan filled with juice and more thoroughly exhausted than the first one, it is clear to see that evaporation at a still lower temperature will be secured. Such a combination as above described is called a double-effect apparatus.

A multiple effect would be a multiplication of pans so connected and manipulated that the steam of one will boil the next. The advantages in such arrangements are: (I) lower temperature and less danger of scorching the contents; (2) speed in evaporating the water from the sweets ; (3) reduction of cost.

Now if syrup be the end aimed at of course the process would end when a proper degree of concentration has been reached. But if it is desired to make sugar also, then additional process must be employed.

III.-Extraction of Sugar.

Under this head we shall give in brief the methods employed with large success at the government experiment stations in 1891 .

The diffusion process affords a juice containing both "sugars" and "non-sugars" in acid aqueous solution. As explained, the acid tends to convert cane sugar into grape sugar, and this is prevented by the use of lime.
The effect of the "non-sugars" is to prevent crystallization and separation of the "sugars" : for this reason they are called molasses-makers (melassigenes). Their removal is necessary to the formation of a large "sugar" product. Their removal is partially accomplished in the processes of defecation, i. e., liming, heating and skimming. But there still remain "nonsugars," which are soluble in water and must be separated in some other way. This is now very successfully accomplished by the use of alcohol. The clarified juices are concentrated until they contain about 55 per cent solid matter, then mixed with an equal volume of $9 \circ$ per cent alcohol, and thoroughly stirred by blowing air through the mixture.

The impurities of the syrup separate in flocculent masses, and in the course of twenty-four hours they completely settle to the bottom of the tanks, leaving a supernatant fluid that is clear and of a pleasant odor.

The next step is to draw off the clear fluid and subject it to distillation, whereby the alcohol is separated and recovered for future use. The sediment is subjected to pressure by which an alcoholic syrup is obtained and a hard cake left containing more or less of sugar and alcohol. Here is the chief loss of alcohol, but the loss may probably be more than replaced by fermentation and distillation of these "press cakes." Here, however, we encounter the United States revenue laws, and modifications would have to be made in the laws before sugar factories could proceed. In fact, the alcoholic process would require so much alcohol that it cannot be profitably employed unless the sugar manufacturer could be allowed to buy, or manufacture, and use alcohol, almost or altogether free of duty. What legislation has been had in regard to this subject we are not prepared to say.

"The syrup, freed from alcohol, was passed through the usual sugar house processes of granulation in the vacuum pan and purging in the centrifugals." (Bulle-

\section{SOFTLY STEALS THE LIGHT OF DAY wher filtered through windows covered with CRYSTOGRAPHS, a substitute for Stained Glass that is inexpensive, beautiful, and easily applied. \\ 20c. per squaxe foot. Samples and catalogue, 100. CRISTOGRAPH CO., \\ 816 North Broad St., Philadelphia.}

\section{Fact and Theory Papers}

I. THE SUPPRESSION OF CON. SUM PTION. BY GODFREY W. HAMBLETON, M.D. $1: 0 \%$. 40c.

11. THE SOCIETY AND THE “FAD." By A PPLETTON MORGAN, Kisq. $12^{\circ}$. 20 cents.

111. PROTOPLASM AND LIFE By c. F. COX. $12^{\circ}$. 75 cents.

IV. THE CHEROKEES IN PRE-COLUMBIAN TIMES. BY CYRUS THoMAS. $12^{\circ}$. $\$ 1$. V. THE TORNADO. By H. A. HAzen.

VI. TIME-RELATIONS OF MENTAL PHENOMENA. BY JOSEPH JASTROW. $12^{\circ}$. 50c. VII. HOUSEHOLD HYGIENE. BY MARY TAYLOR BISSELL. $12^{\circ}$. 75 cents.

\section{N. D. C. HODGES, Publisher, 874 Broadway, New York.}
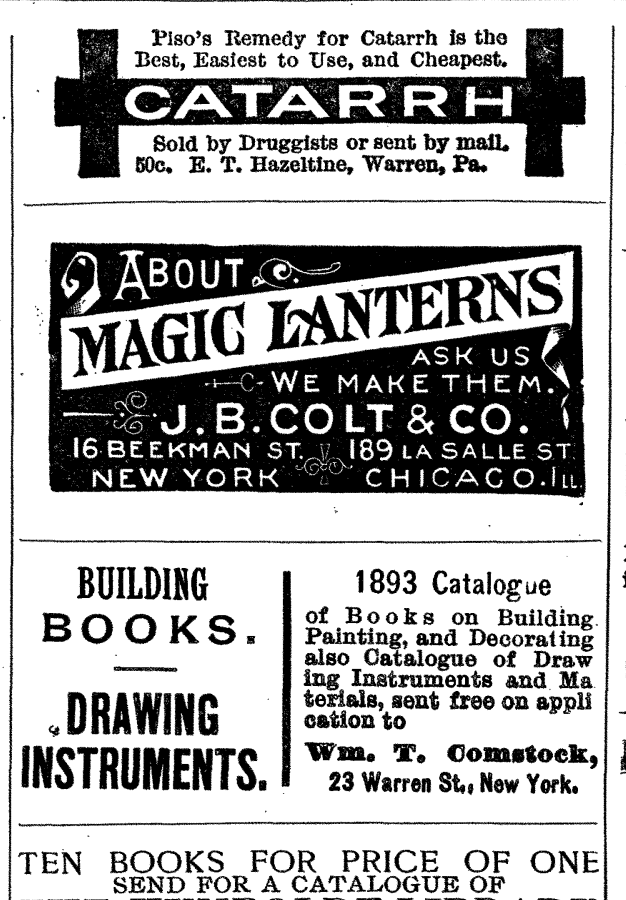
THE HUMBOLDT LIBRARY Containing the works of the foremost scientific writers of the age.- The Great Classics of Moder Thought. - Strong meat for them that are of full ag Address :-THE HUMBOLDT PUBLISHING Co., A monthly magazine for the study ACR $1 / 1$. $A$ of the German language and literaand the press as "the best effort yet made to assist the student of German, and to interest him in his pursuit." "Its BEGINNERs' CoRNkr furnishes every grammar. \$2 a year. Single copies 20 cents. P. O.
Box 151, Manchester, N. H.

Newmpaper Olippingw. 25,000 in Stock. What do you want? Let us know. We can supply you. The demens New" Ageney, Box 2329, San Francisco, Cal."

\section{MIERALS. New store.}

New Stock.

Send for our "Winter Bulletin," recently issued. Minerals, Gems, Microscopical Sections, Fine Lapidary Work.

GEO. L. ENGLSH \& CO., Mineralogists,

Removed to 64 East 12th Street. New York

Pennsylvania Bedford Springs Mineral Wator

For Liver, Kidney and B dder Troubles.

For Gravel, Gall Stones, Jaundice.

For Dyspepsia, Rheumatism and Gout.

For Dropsy, Bright's D

It has been used medicinally and prescribed by physicians for nearly one hundred years.

DIRECTIONS:-Take one or two glasses about

half-hour before each meal.

Case One Dozen Half-Gallon Bottles, $\$ 4.50$

erated), \$7.50.

Bedford Mineral Springs Co., Badfurd, Pa. Philadelphia Office, 1004 . Walnut St. 
tin No. 34, experiments with sorghum in $\mathbf{1} 89 \mathbf{r}$, by Prof. H. W. Wiley.)

The sugar crystallized readily and separated perfectly in the centrifrugals from the syrup in from two to five minutes. By the processes hereinbefore mentioned the sorghum grower of the central States may compete with the grower of ordinary cane in the South. From an acre of good sorghum may be obtained a barrel of nice nearly white sugar, equal in every way to ordinary cane sugar.

The question may arise: "Can the farmer profitably

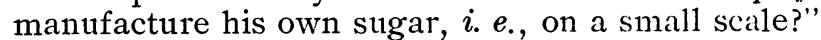

Probably no more than the farmer can manufacture his own woollen goods or make his own flour.

It is doubtful if cane can be profitably raised more than three miles from a central factory, and besides enough cane can be raised within two miles of the factory to supply all of its demands. Such being the fact, the central and northern States must hope to make their own supply of sugar, not by individual factories, but by a system of central factories put up on a large scale and equipped for all the steps of molasses and sugar making.

The amount of sugar consumed in the United States for the year ending June 30 , I 890 , was about three billion pounds (an average of fifty-five pounds per capita), and there were eighty million gallons of molasses consumed.

The United States produced about one-tenth of the sugar and one-fifth of the molasses. Hence the necessity for increasing our sugar producing crops, viz.: the southern cane and the northern sorghum and the beet. $^{1}$

1 To these may be added "corn cane," for a most interesting discussion of which the reader is referred to Science during the montl of September, 1893.
-The third annual meeting of the Ohio Academy of Science was held at Columbus on Dec. 28 and 29,1893 . The usual necessary formal business was done, and papers were read on various subjects connected with geology, botany, entomology, ornithology, and a beginning was made in chemistry and astronomy, which have not previously claimed their fair share of attention. 'The following among the papers read may claim notice here: "On the Evolution of Indian Corn," by Mr. W. A. Kellerman ; "Distribution of North American Lepidoptera in Norway," by Prof. F. M. Webster ; "On Certain New and Known Marine Infusoria," by Dr. D. S. Kellicott ; "Lilke Licking; a Contribution to the Buried Drainage of Ohio," by Prof. W. G. Tight; "Further Study of the Wheat Scale," by Prof. A. D: Selby ; "On a New Fossil Crustacean from the WaterLime," by Irof. E. W. Claypole ; "A Revision of the Lichens of Ohio," by Mr. E. E. Bogue, and "On the Nutritive Value of Common Fruit," by Prof. W. R. Lazenby. Arrangements were also completed for the organization of a Natural History Survey of the State. Three directors were appointed, Professors Claypole, Kellicott and Kellerman, whose duties were simply to enlist and arrange all the volunteer laborers who could be induced to take part in the work and aid them in the choice of fields and in the prosecution of their labors, leaving the whole method or responsibility in their hands as much as if they were independent workers. These results when obtained will be presented to the Academy, by the authors if possible, referred to suitable experts and, at the discretion of the Academy, printed in the annual report. The organization of the undertaking is the most important one of the still young academy. Prof. IF. W. Webster, of the Agricultural Experiment Station, was elected president for I894.

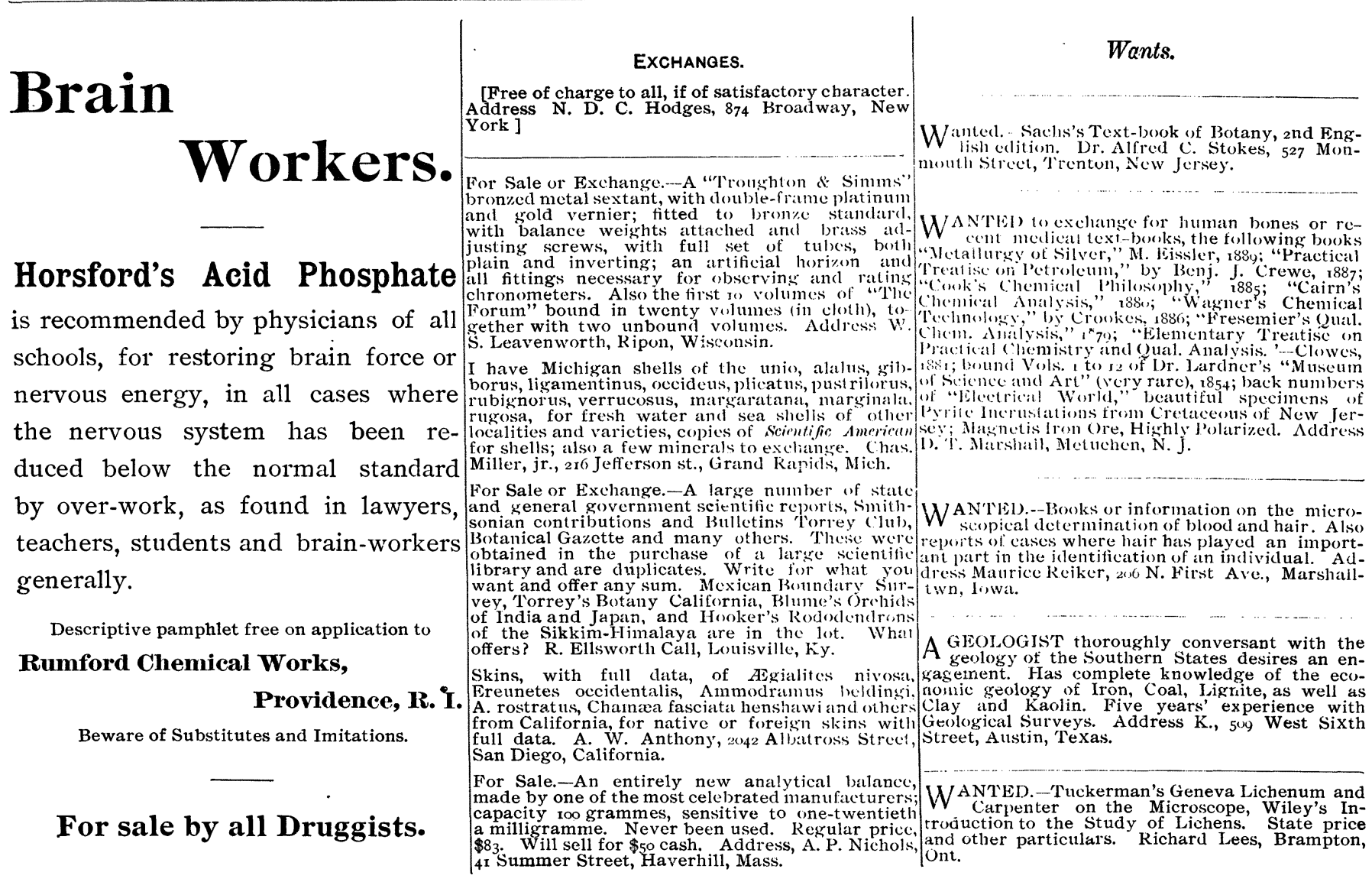

